\title{
Neutron Density Calculation Using the Generalised Adams-Bashforth-Moulton Method
}

\author{
Daniel Suescún-Díaz ${ }^{1, *}$, Diego A. Rasero Causil ${ }^{1}$, Jaime H. Lozano-Parada ${ }^{2}$
}

Edited by

Juan Carlos Salcedo-Reyes

(salcedo.juan@javeriana.edu.co)

1. Department of Natural Sciences, Applied Physics Group, Universidad Surcolombiana, Neiva, Colombia.

2. Institute for Sustainability Studies, Universidad Autónoma de Occidente, Cali, Colombia.

*daniel.suescun@usco.edu.co

Received: 06-06-2018

Accepted: 08-07-2019

Published on line: 20-11-2019

Citation: Suescún-Díaz D, Rasero Causil DA, Lozano-Parada JH.

Neutron Density Calculation Using the Generalised Adams-Bashforth-

Moulton Method,

Universitas Scientiarum, 24 (3): 543-563, 2019. doi: 10.11144/Javeriana.SC24-3.ndcu

Funding:

Applied Physics Research Group of the Surcolombian University

Electronic supplementary material: N.A.

OPEN ACCESS

\begin{abstract}
This paper presents a numerical solution to the equations of point kinetics for nuclear power reactors, a set of seven coupled differential equations that describe the temporal variation of neutron density and the concentration of delayed neutron precursors. Due to the nature of the system, we propose to numerically solve the point kinetics equations by implementing the Adams-Bashforth and Adams-Moulton methods, which are predictor-corrector schemes with their respective modifiers to increase precision. The proposed method was tested computationally for different forms of reactivity with up to six groups of delayed neutron precursors. This method was used in a recent publication to solve the inverse problem of finding the reactivity. In this work, it is shown that it can also be used for the calculation of nuclear power, that it is simple and easy to implement, and that it produces good results when compared with those in the literature for neutron population density and concentration of delayed neutron precursors.
\end{abstract}

Keywords: nuclear reactor power, nuclear density, point kinetics equations, numerical methods.

\section{Introduction}

A nuclear reactor is a device to initiate, control and maintain nuclear fission reactions. The understanding of nuclear fission processes requires the study of the neutron population and the concentration of delayed neutrons, which can be modelled by the equations of point kinetics. The reactor point kinetic equations are the reduced-order model most representative in the nuclear reactor dynamics. 
The calculation of reactivity depends on the neutron density which makes the point kinetics equations nonlinear, and therefore very difficult to solve analytically. The fast and delayed neutron lifetimes are of different orders of magnitude, converting the equations of point kinetics into a stiff system. Several methods have been proposed to solve the equations of point kinetics: In [1], the confinement method (SCM) is proposed to overcome stiffness, whereas other authors have used the generalised Runge-Kutta (GRK) method [2], the Padé approximations [3], the generalization of the analytical inversion method (AIM) [4], and the analytical method (AEM), which used exponential functions [5]. It has also been demonstrated that the point kinetics equations can be solved numerically using the reactivity Piecewise Constant Approximation method (PCA) [6], using a numerical algorithm called: Constant Reactivity (CORE) to calculate nuclear density [7, 8] presented a numerical integral method and investigated the neutron density produced by inserting different forms of reactivity in thermal reactors with multiple groups of the neutrons using the Best Function (BBF). The Taylor series (TSM) was used to calculate the nuclear density with feedback reactivity [9], and the power series method (PWS) has been used to obtain approximate solutions with and without feedback [10-11]. [12] introduced a highly accurate algorithm, combining the Backward Euler Finite Difference method (BEFD) and [13] described a semi-analytical method to solve the equations of point kinetics with a technique called (EPCA) which iteratively corrects the error in the source term with good accuracy. The reduced form of the differential transform method (reduced DT Method) [14] was used to obtain the total neutron density. In [15] the Taylor-Lie series was applied to numerically solve the equations of point kinetics with a quadrature technique. [16] introduced the Haar Wavelet Operational Method (HWOM). In [17] an explicit analytical solution was developed from a Taylor series expansion (ITS2). [18] introduced a new method based on the Trigonometric Fourier Series (TFS) to obtain approximate solutions. In [19] the Exponential Time Differencing Method (ETDM) with a Taylor series approximation was proposed to solve the equations of point kinetics; this is a semi-analytic and self-starting method in which the point kinetic equations are integrated using an integration factor. [20] introduced a matrix form known as Treatment Theta Method (TTM) and in a more recent work the Adams-Bashforth and Adams-Moulton Methods $(\mathrm{ABM})$ were used in nuclear reactivity calculations [21]. Finally, in a recent work [22], neutron density was calculated using the Magnus expansion. This new work proposes to solve the equations of point kinetics for the calculation of nuclear density with the generalised Adams-Bashforth and Adams-Moulton predictor-corrector method of order $\mathrm{O}\left(b^{4}\right)$, with the objective of studying various predictors using the same corrector. This type of multipass method follows a prediction and correction scheme. 
The present work is structured as follows: firstly, a section considering a physical-mathematical model, which contains the theoretical framework and the description of the variables or parameters of the model; secondly, a section with the proposed method, which explains the methodology that was carried out in this research. Finally, a section with the results and conclusions.

\section{Model formulation}

The point kinetics equations describe the time behaviour of the nuclear reactor. These equations are obtained from the equation of neutron diffusion with six groups of delayed neutrons, as given by [23].

$$
\begin{aligned}
& \frac{d P(t)}{d t}=\left[\frac{\rho(t)-\beta}{\Lambda}\right] P(t)+\sum_{i=1}^{6} \lambda_{i} C_{i}(t) \\
& \frac{d C_{i}(t)}{d t}=\frac{\beta_{i}}{\Lambda} P(t)-\lambda_{i} C_{i}(t) i=1,2, \ldots, 6
\end{aligned}
$$

with the following initial conditions:

$$
\begin{array}{r}
P(t=0)=P_{0} \\
C_{i}(t=0)=\frac{\beta_{i}}{\Lambda \lambda_{i}} P_{0}
\end{array}
$$

Where $P(t)$ is neutron density $C_{i}(t)$ is the concentration of the $\mathrm{i}$-th group of delayed neutron precursors, $\rho(t)$ is the reactivity, $\Lambda$ is the neutron generation time, $\beta_{i}$ is the fraction of the $\mathrm{i}$-th delayed neutron group $\beta$ is the total fraction of delayed neutrons, $\left(\beta=\sum_{i} \beta_{i}\right), \lambda_{i}$ is the decay constant of the $\mathrm{i}$-th group of delayed neutron precursors.

\section{Adams-Bashforth and Adams-Moulton Methods}

The Adams-Bashforth-Moulton multistep method (ABM) solves the initial value problem of the form $y^{\prime}=f\left(t_{k}, y_{k}\right)$ using information from points previous to $y_{k}$ to find $y_{k+1}$, generally, these points are obtained with the Runge-Kutta method of order $O\left(b^{4}\right)$. The method of indeterminate coefficients is used to calculate the solution of the function $f\left(t_{k}, y_{k}\right)$, the differential equation with indeterminate coefficients for the generalised fourth-order predictor of the Adams-Bashforth method can be represented by the following equation: 


$$
P_{k+1}=Y_{k+1}=\sum_{i-1}^{4} \alpha_{i} Y_{k+1-i}+b \sum_{i-1}^{4} \beta_{i} y_{k+1-i}^{\prime}+E_{p}
$$

The coefficients $\alpha_{i}, \beta_{i}$ for $i=1, \ldots, 4$ are calculated by carrying out a Taylor series expansion around $h$ on each term $y_{k-1}, y_{k-2}, y_{k-3}, y_{k-1}^{\prime}, y_{k-2}^{\prime} y_{k-3}^{\prime}$, of Eq. (5). We have that

$$
\begin{array}{r}
Y_{k-1}=y_{k}+y_{k}^{\prime}(-i h)+\left(\frac{1}{2 !}\right) y_{k}^{(2)}(-i h)^{2}+\left(\frac{1}{3 !}\right) y_{k}^{(3)}(-i h)^{3}+ \\
\left(\frac{1}{4 !}\right) y_{k}^{(4)}(-i h)^{4}+\left(\frac{1}{5 !}\right) y_{k}^{(5)}(\xi)(-i h)^{5} \\
Y_{k-1}^{\prime}=y_{K}^{\prime}+y_{k}^{(2)}(-i h)+\left(\frac{1}{2 !}\right) y_{k}^{(3)}(-i h)^{2}+\left(\frac{1}{3 !}\right) y_{k}^{(4)}(-i h)^{3}+ \\
\left(\frac{1}{4 !}\right) y_{k}^{(5)}(\xi)(-i h)^{4}
\end{array}
$$

Replacing Eqs. $(6,7)$ into Eq. (5) and equating to the Taylor series for $Y_{k+1}$, that is, making $i=-1$ in Eq. (6), we obtain a set of algebraic equations

$$
\begin{array}{r}
\alpha_{1}+\alpha_{2}+\alpha_{3}+\alpha_{4}=1 \\
-\alpha_{2}-2 \alpha_{3}-3 \alpha_{4}+\beta_{1}+\beta_{2}+\beta_{3}+\beta_{4}=1 \\
\frac{1}{2} \alpha_{2}+2 \alpha_{3}+\frac{9}{2} \alpha_{4}-\beta_{2}-2 \beta_{3}-3 \beta_{4}=\frac{1}{2} \\
-\frac{1}{6} \alpha_{2}-\frac{4}{3} \alpha_{3}-\frac{9}{2} \alpha_{4}+\frac{1}{2} \beta_{2}+2 \beta_{3}+\frac{9}{2} \beta_{4}=\frac{1}{6} \\
\frac{1}{24} \alpha_{2}+\frac{2}{3} \alpha_{3}+\frac{27}{8} \alpha_{4}-\frac{1}{6} \beta_{2}-\frac{4}{3} \beta_{3}-\frac{9}{2} \beta_{4}=\frac{1}{24}
\end{array}
$$

By solving Eqs. (8) we obtain the coefficients/predictors. Table 1 shows these values, which are then replaced into Eq. (5), thus, different predictor formulas can be obtained. For the error estimation, it must be taken into account that

$E_{p}=\frac{E}{5 !} h^{5} y_{k}^{(5)}(\xi)$

Similarly, the corrector of the Adams-Moulton method can be obtained or deduced from the fundamental theorem of calculus, and the Lagrange's interpolator polynomial is given by: 
Table 1. Coefficients of the generalised predictor.

\begin{tabular}{|c|c|c|c|c|c|c|}
\hline Coeficientes \Predictores & $\mathbf{P 1}$ & $\mathbf{P} 2$ & P3 & $\mathbf{P} 4$ & P5 & P6 \\
\hline$\alpha_{1}=1-\alpha_{2}-\alpha_{3}-\alpha_{4}$ & 1 & 0 & 0 & 0 & 0 & $1 / 2$ \\
\hline$\alpha_{2}=\alpha_{2}$ & 0 & 1 & 0 & 0 & $1 / 3$ & $1 / 2$ \\
\hline$\alpha_{3}=\alpha_{3}$ & 0 & 0 & 1 & 0 & $1 / 3$ & 0 \\
\hline$\alpha_{4}=\alpha_{4}$ & 0 & 0 & 0 & 1 & $1 / 3$ & 0 \\
\hline$\beta_{1}=(1 / 24)\left(55+9 \alpha_{2}+8 \alpha_{3}+9 \alpha_{4}\right)$ & $55 / 24$ & $8 / 3$ & $21 / 8$ & $8 / 3$ & $191 / 72$ & $119 / 48$ \\
\hline$\beta_{2}=(1 / 24)\left(-59+19 \alpha_{2}+32 \alpha_{3}+27 \alpha_{4}\right)$ & $-59 / 24$ & $-5 / 3$ & $-9 / 8$ & $-4 / 3$ & $-11 / 8$ & $-99 / 48$ \\
\hline$\beta_{3}=(1 / 24)\left(37+5 \alpha_{2}+8 \alpha_{3}+27 \alpha_{4}\right)$ & $37 / 24$ & $4 / 3$ & $15 / 8$ & $8 / 3$ & $47 / 24$ & $69 / 48$ \\
\hline$\beta_{4}=(1 / 24)\left(-9+\alpha_{2}+9 \alpha_{4}\right)$ & $-9 / 24$ & $-1 / 3$ & $-3 / 8$ & 0 & $-17 / 72$ & $-17 / 48$ \\
\hline$E=(1 / 6)\left(251-19 \alpha_{2}-8 \alpha_{3}-27 \alpha_{4}\right)$ & $251 / 6$ & $116 / 3$ & $243 / 6$ & $224 / 6$ & $233 / 6$ & $116 / 4$ \\
\hline
\end{tabular}

$$
Y_{k+1}=y_{k}+\frac{b}{24}\left(9 y_{k+1}^{\prime}+19 y_{k}^{\prime}-5 y_{k-1}^{\prime}+y_{k-2}^{\prime}\right)
$$

The truncation error of Eq. (9) is:

$$
E_{c}=-\frac{19}{720} h^{5} y_{k}^{(5)}(\xi)
$$

The method's convergence criterion is obtained by making successive adjustments to the corrector in the following way:

$$
\begin{array}{r}
y_{\alpha}-y_{c}=\left(y_{k}+\frac{b}{24}\left(9 y_{c}^{\prime}+19 y_{k}^{\prime}-5 y_{k-1}^{\prime}+y_{k-2}^{\prime}\right)\right) \\
-\left(y_{k}+\frac{b}{24}\left(9 y_{p}^{\prime}+19 y_{k}^{\prime}-5 y_{k-1}^{\prime}+y_{k-2}^{\prime}\right)\right) \\
=\frac{9 b}{24}\left(y_{c}^{\prime}-y_{p}^{\prime}\right)
\end{array}
$$

where,

$y_{p}, y_{c}$ are values in the predictor-corrector formulas, $y_{c c}$ is the first correction in the corrector 
After some algebraic manipulation, Eq. (11) can be written as:

$$
y_{c c}-y_{c}=\frac{9 h D}{24} f_{y}(\xi)
$$

where, $D=y_{c}-y_{p}, \xi \in\left[y_{c}, y_{p}\right]$. After a new correction, the result will be:

$$
y_{c c c}-y_{c c}=\frac{9 h}{24}\left(y_{c c}^{\prime}-y_{c}^{\prime}\right)=\left(\frac{9 b}{24}\right)^{2}\left[f_{y}(\xi)\right]^{2} D
$$

Thus, by adding all the corrections, a geometric series with ratio $r$ arises

$$
r=\frac{9 h f_{y}(\xi)}{24}
$$

In order for the geometric series as given by Eq. (14) to converge, we must have $r<1$. Rearranging for $b$ gives the convergence criteria as

$$
b \leq \frac{24}{9\left|f_{y}(t, y)\right|}
$$

The case predictor proposed (P3), is selected from Table 1, obtaining:

$$
p_{k+1}=y_{k-2}+\frac{b}{8}\left(21 y_{k}^{\prime}-9 y_{k-1}^{\prime}+15 y_{k-2}^{\prime}-3 y_{k-3}^{\prime}\right)
$$

The predictor error of Eq. (16) is given by:

$$
E_{p}=\frac{243}{720} h^{5} y_{k}^{(5)}(\xi)
$$

In order to obtain better results, we can find the corrector's modifier and the predictor in the following way

$$
y\left(t_{k+1}\right)=p_{k+1}+E_{p}=y_{k+1}+E_{c}
$$

where $y\left(t_{k+1}\right)$ is the exact value.

Replacing Eq. (10) and Eq. (17) into Eq. (18), we get:

$$
\begin{array}{r}
p_{k+1}-y_{k+1}=E_{c}-E_{p}=-\frac{19}{720} h^{5} y_{k}^{(5)}(\xi)-\frac{243}{720} h^{5} y_{k}^{(5)}(\xi)= \\
-\frac{262}{720} h^{5} y_{k}^{(5)}(\xi)
\end{array}
$$


The term that contains the derivative can be expressed as

$$
\frac{720}{262}\left(p_{k+1}-y_{k+1}\right)=-b^{5} y_{k}^{(5)} \xi
$$

Multiplying Eq. (20) by $\frac{19}{720}$, and making use of Eq. (10) we get

$$
\frac{19}{262}\left(p_{k+1}-y_{k+1}\right)=-\frac{19}{720} b^{5} y_{k}^{(5)}(\xi)=E_{c}
$$

By replacing Eq. (21) into Eq. (18) we get

$$
y\left(t_{k+1}\right)=y_{k+1}+e_{c}=y_{k+1}+\frac{19}{262}\left(P_{k+1}-y_{k+1}\right)
$$

Adding $-p_{k+1}$ to both sides of Eq. (22) we get

$$
y\left(t_{k+1}\right) \approx P_{k+1}+\frac{243}{262}\left(y_{k+1}-P_{k+1}\right)
$$

Eq. (23) can be used to improve the value of the predictor and to estimate the error both in the predictor and the corrector, without having to calculate the fifth derivative. A slow change in the difference between the predictor and corrector from one step to the next is assumed. Then $P_{k+1}$ is replaced by $P_{k}, y_{k+1}$ by $y_{k}$ in Eq. (23) to obtain the following modified formula for the predictor:

$$
m p_{k+1}=p_{k+1}+\frac{243}{262}\left(y_{k}-p_{k}\right)
$$

Similarly, the modified formula for the corrector is:

$$
m y_{k+1}=y_{k+1}-\frac{19}{262}\left(y_{k+1}-p_{k+1}\right)
$$

\section{Results and discussion}

The Adams-Bashforth-Moulton method is applied to solve the equations of point kinetics with one or six groups of delayed neutrons. Three cases of reactivity functions are presented: step, ramp and sinusoidal. Each case will be studied separately and the results will be compared to other methods available in the literature. 


\section{Step Reactivity}

For the neutron density calculation the following parameters for a thermal reactor are considered: $\lambda_{1}=0.0127 \mathrm{~s}^{-1}, \lambda_{2}=0.0317 \mathrm{~s}^{-1}, \lambda_{3}=0.115 \mathrm{~s}^{-1}$, $\lambda_{4}=0.311 \mathrm{~s}^{-1}, \lambda_{5}=1.4 \mathrm{~s}^{-1}, \lambda_{6}=3.87 \mathrm{~s}^{-1}, \beta_{1}=0.0000266, \beta_{2}=0.001491$, $\beta_{3}=0.001316, \beta_{4}=0.002848, \beta_{5}=0.000896, \beta_{6}=0.000182, \beta=0.007$, $\Lambda=2 \times 10^{-5}$ s.

Table 2 and Table 3 show different values for neutron density with reactivities of $300 \mathrm{pcm}=0.43(\$)$ and $700 \mathrm{pcm}$ (parts per hundred thousand) $=1(\$)$ reported in the literature [17], these are values for critical and subcritical reactors. The dollar symbol $1(\$)$ is equivalent to $1 \beta=0.007$. The step size in the proposed ABM method is $h=10^{-3} s$, unfortunately, the authors do not show the time step used in their reported methods. Fig. 1 shows how stiffness forces an abrupt change in the neutron density for a reactivity of 300 $\mathrm{pcm}=0.43$ (\$). This is due to the big differences between $\Lambda=5 \times 10^{-4} s$ and $1 / \lambda_{i}$.

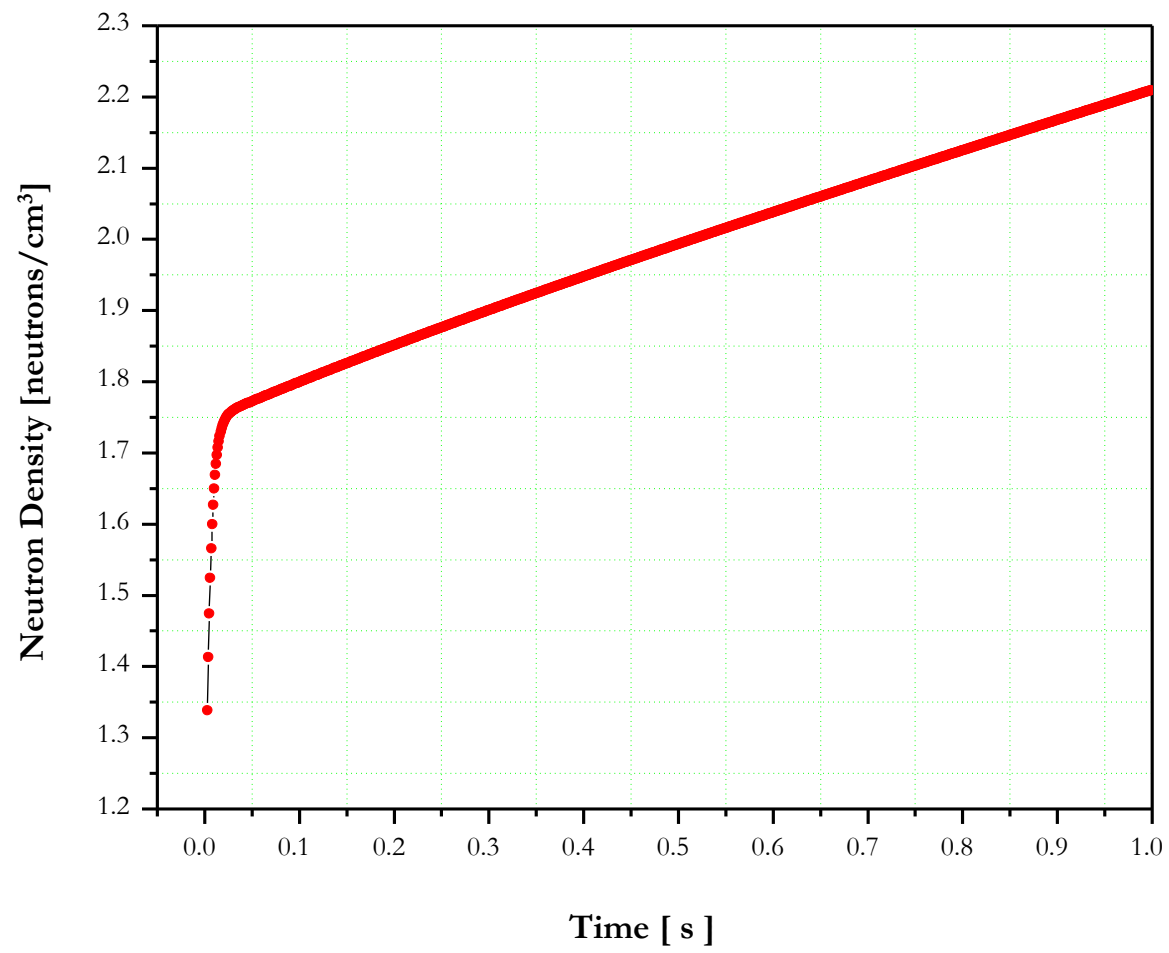

Figure 1. Neutron density for reactivity $\rho=0.43(\$)$. 
Table 2. Neutron density for reactivity $\rho=0.43(\$)$.

\begin{tabular}{lcccc}
\hline \multicolumn{1}{c}{$\mathbf{c}(\mathbf{s})$} & \multicolumn{1}{c}{$\mathbf{0 . 4}$} & \multicolumn{1}{c}{$\mathbf{0 . 6}$} & \multicolumn{1}{c}{$\mathbf{0 . 8}$} & \multicolumn{1}{c}{$\mathbf{1 . 0}$} \\
\hline BBF & 1.947585 & 2.037917 & 2.124829 & 2.209839 \\
\hline Taylor & 1.947581 & 2.037915 & 2.124827 & 2.209838 \\
\hline End Floating & 1.947586 & 2.037918 & 2.124829 & 2.209839 \\
\hline ITS2 & 1.94759341138 & 2.03792205592 & 2.12483163642 & 2.20984045698 \\
\hline ABM & 1.94759341122 & 2.03792205578 & 2.12483163628 & 2.20984045684 \\
\hline
\end{tabular}

The ABM method can be applied to a thermal reactor with the values obtained in Yun Cai et al. [22] using the ME3, PCA / ME2 and EPCA methods. The values of the kinetic parameters are: $\lambda_{1}=0.0127 \mathrm{~s}^{-1}, \lambda_{2}=0.0317 \mathrm{~s}^{-1}$, $\lambda_{3}=0.115 \mathrm{~s}^{-1}, \lambda_{4}=0.311 \mathrm{~s}^{-1}, \lambda_{5}=1.4 \mathrm{~s}^{-1}, \lambda_{6}=3.87 \mathrm{~s}^{-1}, \beta_{1}=0.000285, \beta_{2}=$ $0.0015975, \beta_{3}=0.00141, \beta_{4}=0.0030535, \beta_{5}=0.00096, \beta_{6}=0.000195, \beta=$ $0.0075, \Lambda=5 \times 10^{-4}$ s. Table 4 shows the results obtained with the ABM method and those reported in the literature for a reactivity $\rho=1(\$)$.

\section{Ramp reactivity}

In this section, the behaviour of the neutron density is determined for ramp reactivities of two types: moderately fast and very fast, which correspond to thermal and fast reactors, respectively.

In the case of moderately fast ramp reactivities, the parameters for the thermal reactor are obtained from [17]: $\lambda_{1}=0.0127 \mathrm{~s}^{-1}, \lambda_{2}=0.0317 \mathrm{~s}^{-1}, \lambda_{3}=0.115$ $\mathrm{s}^{-1}, \lambda_{4}=0.311 \mathrm{~s}^{-1}, \lambda_{5}=1.4 \mathrm{~s}^{-1}, \lambda_{6}=3.87 \mathrm{~s}^{-1}, \beta_{1}=0.000266, \beta_{2}=$ $0.001491, \beta_{3}=0.001316, \beta_{4}=0.002848, \beta_{5}=0.000896, \beta_{6}=0.000182, \beta=$ $0.007, \Lambda=2 \times 10^{-5} s$. Table 5 and Table 6 show the calculation of neutron density given a reactivity of the form $\rho(t)=0.0007 * t$, in this case $\rho=0.1(\$) / \mathrm{s}$. The results using the proposed ABM method are compared with the values reported in references [17] and [22]. The proposed method uses the step size $h=10^{-3} s$ again. It is observed that the ABM method is very accurate when compared to other methods in the literature. For this type of reactivity, the neutron density increases exponentially in such a way that for a time $t=9 \mathrm{~s}$ there are approximately 487 neutrons / $\mathrm{cm}^{3}$, as can be observed in Fig. 2. 
Table 3. Neutron density for reactivity $\rho=1(\$)$.

\begin{tabular}{|lcccc}
\hline \multicolumn{1}{c}{$\mathbf{c}(\mathbf{s})$} & \multicolumn{1}{c}{$\mathbf{0 . 4}$} & \multicolumn{1}{c}{$\mathbf{0 . 6}$} & \multicolumn{1}{c}{$\mathbf{0 . 8}$} & \multicolumn{1}{c}{$\mathbf{1 . 0}$} \\
\hline BBF & 0.4652904 & 0.4519648 & 0.4402728 & 0.429 .7825 \\
\hline Taylor & 0.4652909 & 0.4519651 & 0.4402731 & 0.429 .7827 \\
\hline End Floating & 0.4652904 & 0.4519647 & 0.4402727 & 0.429 .7824 \\
\hline ITS2 & 0.465289326117 & 0.451963975793 & 0.440272277652 & 0.429 .782046265 \\
\hline ABM & 0.465289326298 & 0.451963975950 & 0.440272277791 & 0.429 .782046391 \\
\hline
\end{tabular}

In the case of very fast ramp reactivities, the $A B M$ method can be applied to a fast reactor with the parameters obtained in Picca [13] using the EPCA method, and from Yun Cai et al. [22] using the ME3 and PCA/ME2 methods. The values of the kinetic parameters are: $\lambda_{1}=0.0129 \mathrm{~s}^{-1}, \lambda_{2}=0.0311 \mathrm{~s}^{-1}, \lambda_{3}=0.134 \mathrm{~s}^{-1}, \lambda_{4}=0.331 \mathrm{~s}^{-1}$,

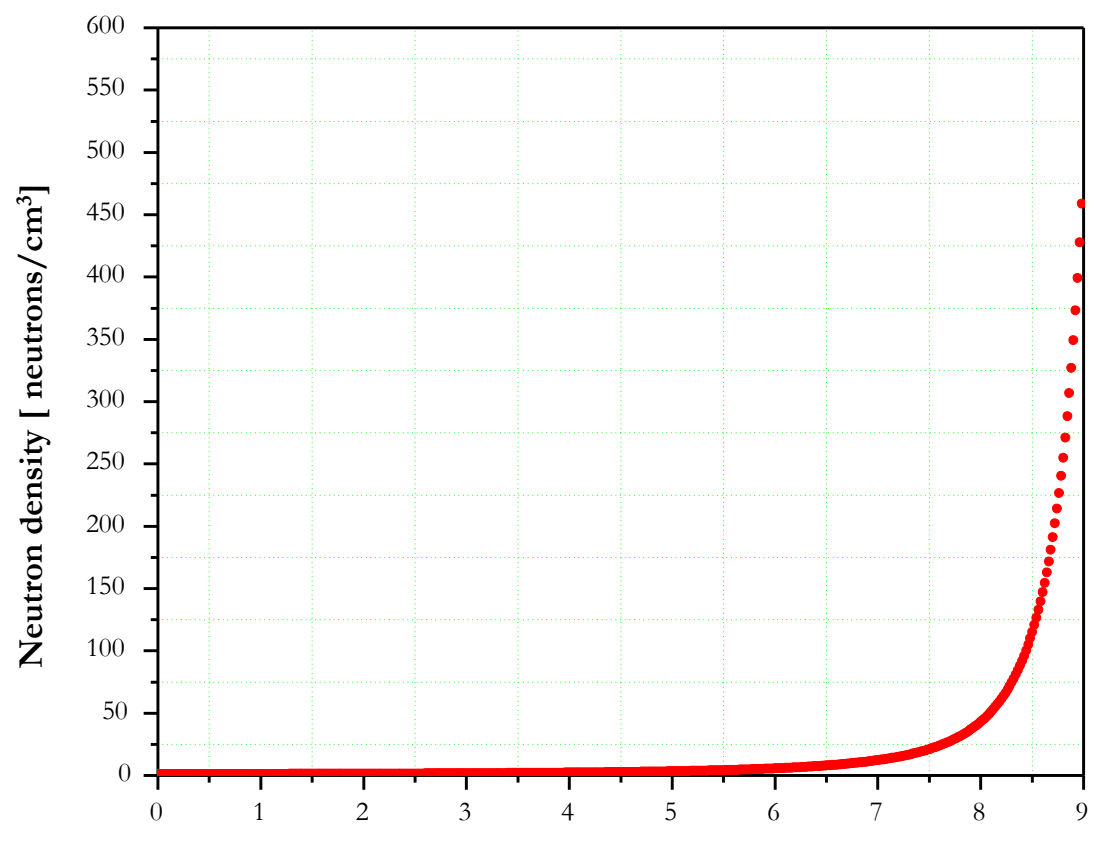

Time [ $\mathrm{s}]$

Figure 2. Neutron density obtained with a reactivity of $\rho=0.1(\$)$. 
Table 4. Neutron density for reactivity $\rho=1(\$)$.

\begin{tabular}{cccc}
\hline t(s) & PCA $/$ ME2 & ME3 & BEFD \\
\hline 0.1 & $2.515766141 \mathrm{e}+0$ & $2.515766141 \mathrm{e}+0$ & $2.515766141 \mathrm{e}+0$ \\
\hline 0.5 & $1.036253381 \mathrm{e}+1$ & $1.036253381 \mathrm{e}+1$ & $1.036253381 \mathrm{e}+1$ \\
\hline 1.0 & $3.218354095 \mathrm{e}+1$ & $3.218354095 \mathrm{e}+1$ & $3.218354095 \mathrm{e}+01$ \\
\hline 10 & $3.246978898 \mathrm{e}+9$ & $3.246978898 \mathrm{e}+9$ & $3.246978898 \mathrm{e}+09$ \\
\hline 100 & $2.596484647 \mathrm{e}+89$ & $2.596484647 \mathrm{e}+89$ & $2.596484647 \mathrm{e}+89$ \\
\hline
\end{tabular}

\begin{tabular}{cccc}
\hline $\mathbf{t}(\mathbf{s})$ & $\begin{array}{c}\mathbf{A B M} \\
(\mathbf{h}=\mathbf{0 . 1} \mathbf{s})\end{array}$ & $\begin{array}{c}\mathbf{A B M} \\
\mathbf{( h = 0 . 0 1} \mathbf{s})\end{array}$ & $\begin{array}{c}\mathbf{A B M} \\
(\mathbf{h}=\mathbf{0 . 0 0 1} \mathbf{~ s})\end{array}$ \\
\hline 0.1 & $2.515682234 \mathrm{e}+0$ & $2.515766144 \mathrm{e}+0$ & $2.515766141 \mathrm{e}+0$ \\
\hline 0.5 & $1.036240672 \mathrm{e}+1$ & $1.036253383 \mathrm{e}+1$ & $1.036253381 \mathrm{e}+1$ \\
\hline 1.0 & $3.218326024 \mathrm{e}+1$ & $3.218354105 \mathrm{e}+1$ & $3.218354095 \mathrm{e}+1$ \\
\hline 10 & $3.247549087 \mathrm{e}+1$ & $3.246979019 \mathrm{e}+9$ & $3.246978898 \mathrm{e}+9$ \\
\hline 100 & $2.601738443 \mathrm{e}+89$ & $2.596485635 \mathrm{e}+89$ & $2.596484647 \mathrm{e}+89$ \\
\hline
\end{tabular}

$\lambda_{5}=1.26 \mathrm{~s}^{-1}, \lambda_{6}=3.21 \mathrm{~s}^{-1}, \beta_{1}=0.0001672, \beta_{2}=0.001232, \beta_{3}=$ $0.0009504, \beta_{4}=0.001443, \beta_{5}=0.0004534, \beta_{6}=0.0001541, \beta=$ $0.00440, \Lambda=1 \times 10^{-7} \mathrm{~s}$. Table 7 shows the results obtained with the ABM method and those reported in the literature for a reactivity $\rho=1(\$) / \mathrm{s}$.

\section{Sinusoidal Reactivity}

In order to validate the ABM approach, the results obtained for the sinusoidal reactivity are compared with the results obtained in [13] and [22] using the ME3, PCA / ME2 and EPCA methods with nonlinear reactivity insertion for a fast reactor with the following parameters: where $\lambda_{1}=0.077 \mathrm{~s}^{-1}, \beta=$ $\beta_{1}=0.0079, \Lambda=1 \times 10^{-6}$ s. The results are shown in Table 8 .

Another validation for the approximation of the ABM method consists in comparing it with the results obtained in [19] using the ETD and TSM methods with nonlinear reactivity insertion for a thermal reactor with the following parameters: $\lambda_{1}=0.0127 \mathrm{~s}^{-1}, \lambda_{2}=0.0317 \mathrm{~s}^{-1}, \lambda_{3}=0.115 \mathrm{~s}^{-1}$, 
Table 5. Neutron density obtained with a reactivity of $\rho=0.1(\$) / \mathrm{s}$.

\begin{tabular}{|c|c|c|c|}
\hline$t(s)$ & ITS2 & $\begin{array}{c}\text { GRK } \\
(\mathrm{h}=0.056 \mathrm{~s})\end{array}$ & $\begin{array}{c}\text { pws } \\
(\mathrm{h}=0.01 \mathrm{~s})\end{array}$ \\
\hline 2.0 & $1.338200050 \mathrm{e}+0$ & $1.3382 \mathrm{e}+0$ & $1.3382 \mathrm{e}+0$ \\
\hline 4.0 & $2.228441897 \mathrm{e}+0$ & $2.2284 \mathrm{e}+0$ & $2.2284 \mathrm{e}+0$ \\
\hline 6.0 & $5.582052449 \mathrm{e}+0$ & $5.5820 \mathrm{e}+0$ & $5.5820 \mathrm{e}+0$ \\
\hline 8.0 & $4.278629573 e+1$ & $4.2786 \mathrm{e}+1$ & $4.2786 \mathrm{e}+1$ \\
\hline 10.0 & $4.511636239 e+5$ & $4.5115 \mathrm{e}+5$ & $4.5116 \mathrm{e}+5$ \\
\hline 11.0 & $1.792213608 e+16$ & $1.7904 \mathrm{e}+16$ & $1.7921 \mathrm{e}+16$ \\
\hline$t(s)$ & $\begin{array}{c}\Theta \text {-Weighting } \\
(\mathrm{h}=0.0001)\end{array}$ & $\begin{array}{c}\text { AIM } \\
(h=0.001 \mathrm{~s})\end{array}$ & $\begin{array}{c}\text { ABM } \\
(h=0.001 \mathrm{~s})\end{array}$ \\
\hline 2.0 & $1.3382 \mathrm{e}+0$ & $1.3382 \mathrm{e}+0$ & $1.338200011 \mathrm{e}+0$ \\
\hline 4.0 & $2.2283 \mathrm{e}+0$ & $2.2284 \mathrm{e}+0$ & $2.228441842 \mathrm{e}+0$ \\
\hline 6.0 & $5.5815 \mathrm{e}+0$ & $5.5820 \mathrm{e}+0$ & $5.582052323 \mathrm{e}+0$ \\
\hline 8.0 & $4.2781 \mathrm{e}+1$ & $4.2786 \mathrm{e}+1$ & $4.278629479 \mathrm{e}+1$ \\
\hline 10.0 & $4.5109 \mathrm{e}+5$ & $4.5116 \mathrm{e}+5$ & $4.511636145 e+5$ \\
\hline 11.0 & $1.7919 \mathrm{e}+16$ & $1.7916 \mathrm{e}+16$ & $1.792213979 \mathrm{e}+16$ \\
\hline
\end{tabular}

$\lambda_{4}=0.311 \mathrm{~s}^{-1}, \lambda_{5}=1.4 \mathrm{~s}^{-1}, \lambda_{6}=3.87 \mathrm{~s}^{-1}, \beta_{1}=0.000266, \beta_{2}=0.001491, \beta_{3}=$ $0.001316, \beta_{4}=0.002848, \beta_{5}=0.000896, \beta_{6}=0.000182, \beta=0.007, \Lambda=$ $2 \times 10^{-5} s, \rho(t)=\rho_{o} \operatorname{Sin}(4 \pi t)$ where $\rho_{o}=0.001$. These results are shown in Table 9. This form of inserted reactivity produces an oscillation in the neutron population density, as can be seen in Fig. 3 .

The results presented using the proposed method of ABM of order 4 can be summarised in the following way: using a time step $b=0.001$ s, for thermal reactors with Step Reactivity, at least nine significant figures could be obtained. For Ramp Reactivity for thermal and fast reactors, at least six significant figures are obtained in the numerical experiments. Finally, three significant figures are obtained for experiments with Sinusoidal Reactivity for thermal and fast reactors. For all the experiments performed in this work, better results can be achieved with a time step $b=0.0001 \mathrm{~s}$. 
Table 6. Neutron density obtained with a reactivity of $\rho=0.43(\$)$.

\begin{tabular}{ccccc}
\hline t(s) & $\begin{array}{c}\text { ME3 } \\
(\mathbf{h}=\mathbf{0 . 0 0 1} \mathbf{~})\end{array}$ & $\begin{array}{c}\text { PCA/ME2 } \\
(\mathbf{h}=\mathbf{0 . 0 0 1} \mathbf{~})\end{array}$ & TSM \\
\hline 2.0 & $1.338200055 \mathrm{e}+0$ & $1.338196154 \mathrm{e}+0$ & $1.3382 \mathrm{e}+0$ \\
\hline 4.0 & $2.228441902 \mathrm{e}+0$ & $2.228435405 \mathrm{e}+0$ & $2.2284 \mathrm{e}+0$ \\
\hline 6.0 & $5.582052454 \mathrm{e}+0$ & $5.582036180 \mathrm{e}+0$ & $5.5822 \mathrm{e}+0$ \\
\hline 8.0 & $4.278629574 \mathrm{e}+1$ & $4.278617100 \mathrm{e}+1$ & $4.2789 \mathrm{e}+1$ \\
\hline 10.0 & $4.511636239 \mathrm{e}+5$ & $4.511623086 \mathrm{e}+5$ & $4.5143 \mathrm{e}+5$ \\
\hline 11.0 & $1.792213607 \mathrm{e}+16$ & $1.792208382 \mathrm{e}+16$ & $\mathrm{NA}$ \\
\hline
\end{tabular}

\begin{tabular}{ccccc}
\hline $\mathbf{t}(\mathbf{s})$ & $\mathbf{B B F}$ & $\mathbf{B E F D}$ & $\begin{array}{c}\text { ABM } \\
(\mathbf{h}=\mathbf{0 . 0 0 1} \mathbf{~ s})\end{array}$ \\
\hline 2.0 & $1.3382 \mathrm{e}+0$ & $1.338200050 \mathrm{e}+0$ & $1.338200011 \mathrm{e}+0$ \\
\hline 4.0 & $2.2284 \mathrm{e}+0$ & $2.228441897 \mathrm{e}+0$ & $2.228441842 \mathrm{e}+0$ \\
\hline 6.0 & $5.5820 \mathrm{e}+0$ & $5.582052449 \mathrm{e}+0$ & $5.582052323 \mathrm{e}+0$ \\
\hline 8.0 & $4.2786 \mathrm{e}+1$ & $4.278629573 \mathrm{e}+1$ & $4.278629479 \mathrm{e}+1$ \\
\hline 10.0 & $4.5041 \mathrm{e}+5$ & $4.511636239 \mathrm{e}+5$ & $4.511636145 \mathrm{e}+5$ \\
\hline 11.0 & NA & $1.792213607 \mathrm{e}+16$ & $1.792213979 \mathrm{e}+16$ \\
\hline
\end{tabular}

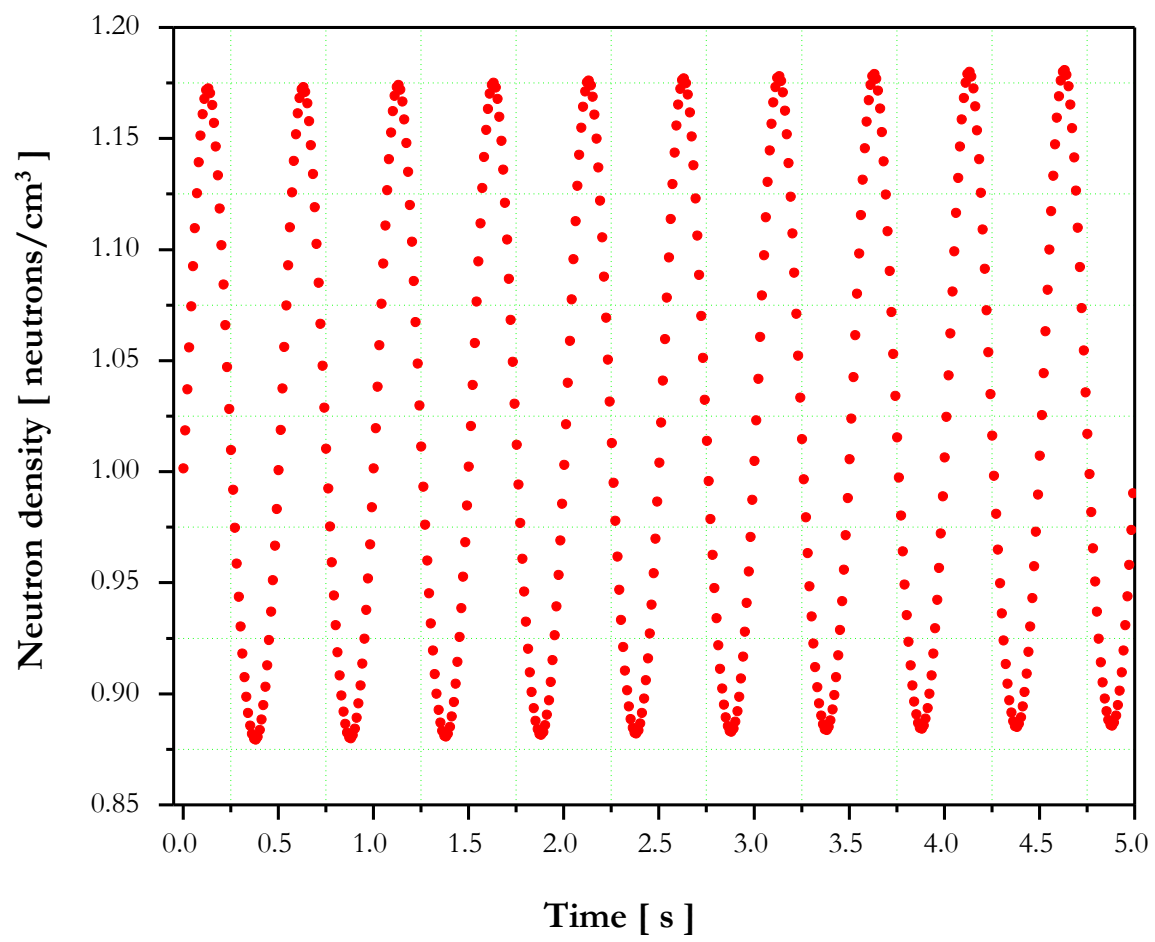

Figure 3. Neutron density for a thermal reactor with sinusoidal reactivity. 
Table 7. Neutron density for reactivity $\rho=1(\$)$.

\begin{tabular}{|cccccc}
\hline $\mathbf{t}(\mathbf{s})$ & $\begin{array}{c}\mathbf{P C A} / \mathbf{M E 2} \\
(\mathbf{h}=\mathbf{0 . 0 0 0 1} \mathbf{s})\end{array}$ & $\begin{array}{c}\mathbf{M E 3} \\
(\mathbf{h}=\mathbf{0 . 0 0 0 1} \mathbf{s})\end{array}$ & $\begin{array}{c}\text { EPCA } \\
(\mathbf{h}=\mathbf{0 . 0 0 0 0 1} \mathbf{s})\end{array}$ & $\begin{array}{c}\text { ABM } \\
(\mathbf{h}=\mathbf{0 . 0 0 0 0 1} \mathbf{~})\end{array}$ \\
\hline 0.01 & $1.010068194 \mathrm{e}+0$ & $1.010105230 \mathrm{e}+0$ & $1.010097112 \mathrm{e}+0$ & $1.010097111 \mathrm{e}+0$ \\
\hline 0.1 & $1.113287096 \mathrm{e}+0$ & $1.113327917 \mathrm{e}+0$ & $1.113320113 \mathrm{e}+0$ & $1.113320112 \mathrm{e}+0$ \\
\hline 0.2 & $1.260521100 \mathrm{e}+0$ & $1.260567318 \mathrm{e}+0$ & $1.260559925 \mathrm{e}+0$ & $1.260559925 \mathrm{e}+0$ \\
\hline 0.5 & $2.136336445 \mathrm{e}+0$ & $2.136414776 \mathrm{e}+0$ & $2.136409108 \mathrm{e}+0$ & $2.136409107 \mathrm{e}+0$ \\
\hline 1.0 & $1.207769913 \mathrm{e}+3$ & $1.207814194 \mathrm{e}+3$ & $1.207814198 \mathrm{e}+3$ & $1.207814197 \mathrm{e}+3$ \\
\hline 1.1 & $3.257473916 \mathrm{e}+99$ & $3.257593342 \mathrm{e}+99$ & $3.257593356 \mathrm{e}+99$ & $3.257601607 \mathrm{e}+99$ \\
\hline 1.15 & $1.028937632 \mathrm{e}+219$ & $1.028975355 \mathrm{e}+219$ & $1.028975360 \mathrm{e}+219$ & $1.029000660 \mathrm{e}+219$ \\
\hline
\end{tabular}

Table 8. Neutron density for a fast reactor with sinusoidal reactivity.

\begin{tabular}{|ccccc}
\hline $\mathbf{t}(\mathbf{s})$ & $\begin{array}{c}\text { ME3 } \\
(\mathbf{h}=\mathbf{0 . 0 0 1} \mathbf{s})\end{array}$ & $\begin{array}{c}\text { PCA } \mathbf{M E 2} \\
\mathbf{( h = 0 . 0 0 1} \mathbf{s})\end{array}$ & $\begin{array}{c}\text { EPCA } \\
(\mathbf{h}=\mathbf{0 . 0 0 0 1} \mathbf{s})\end{array}$ & $\begin{array}{c}\text { ABM } \\
(\mathbf{h}=\mathbf{0 . 0 0 0 1} \mathbf{s})\end{array}$ \\
\hline 10 & $2.065322671 \mathrm{e}+0$ & $2.065276012 \mathrm{e}+0$ & $2.065311114 \mathrm{e}+0$ & $2.065311114 \mathrm{e}+0$ \\
\hline 20 & $8.852839730 \mathrm{e}+0$ & $8.852763321 \mathrm{e}+0$ & $8.852831171 \mathrm{e}+0$ & $8.852831171 \mathrm{e}+0$ \\
\hline 30 & $4.063324406 \mathrm{e}+1$ & $4.063359451 \mathrm{e}+1$ & $4.063328342 \mathrm{e}+1$ & $4.063328342 \mathrm{e}+1$ \\
\hline 40 & $6.134100265 \mathrm{e}+1$ & $6.134238819 \mathrm{e}+1$ & $6.134134599 \mathrm{e}+1$ & $6.134134599 \mathrm{e}+1$ \\
\hline 50 & $4.609503985 \mathrm{e}+1$ & $4.609632692 \mathrm{e}+1$ & $4.609559630 \mathrm{e}+1$ & $4.609559630 \mathrm{e}+1$ \\
\hline
\end{tabular}


Table 9. Neutron density for a thermal reactor with sinusoidal reactivity.

\begin{tabular}{|c|c|c|c|}
\hline$t(s)$ & $\begin{array}{c}\text { Modified ETD }(\mathrm{S}=7) \\
\mathrm{h}=0.001 \mathrm{~s}\end{array}$ & $\begin{array}{c}\text { TSM } \\
(h=0.001 s)\end{array}$ & $\begin{array}{c}\text { ABM } \\
(h=0.001 s)\end{array}$ \\
\hline 0.0 & 1.0000000 & 1.0000000 & 1.0000000 \\
\hline 0.4 & 0.8828488 & 0.8828564 & 0.8825163 \\
\hline 0.8 & 0.9334387 & 0.9333666 & 0.9346909 \\
\hline 1.2 & 1.1070115 & 1.1069329 & 1.1086086 \\
\hline 1.6 & 1.1615297 & 1.1615597 & 1.1606478 \\
\hline 2.0 & 0.9992939 & 0.9993774 & 0.9976047 \\
\hline 2.4 & 0.8857330 & 0.8857506 & 0.8854093 \\
\hline 2.8 & 0.9366979 & 0.9366357 & 0.9379546 \\
\hline 3.2 & 1.1108737 & 1.1107949 & 1.1124749 \\
\hline 3.6 & 1.1653616 & 1.1654019 & 1.1644848 \\
\hline 4.0 & 1.0024811 & 1.0025649 & 1.0007863 \\
\hline 4.4 & 0.8885748 & 0.8885925 & 0.8882507 \\
\hline 4.8 & 0.9397346 & 0.9396721 & 0.9410057 \\
\hline 5.0 & 1.0039612 & 1.0040551 & 1.0022639 \\
\hline
\end{tabular}

\section{Conclusions}

In this paper, the generalised predictor of the Adams-Bashforth-Moulton method (ABM) was presented. This is a method based upon prediction and correction, that guarantees a higher precision when numerically solving a system of differential equations, in this case applied to the point kinetics equations. The results were presented for case P3 of Table 1, since the other cases had a similar approximation. Different time steps were used to perform the numerical simulations; however, the best results were obtained for $h=10^{-3}$, which allowed the comparison with the results reported in the literature. The values of nuclear power obtained with the proposed method agree very well with those found in the literature for different forms of reactivity, for both thermal and fast reactors. It is concluded that the method can be used to calculate nuclear density under different values of reactivity. 


\section{Acknowledgements}

This work was supported by the Applied Physics Research Group of the Surcolombian University, Neiva, Colombia.

\section{References}

[1] Chao YA, Attard A. A resolution of the stiffness problem of reactor kinetics, Nuclear Science and Engineering, 90(1):40-46, 1985. doi: 10.13182/NSE85-A17429

[2] Sánchez J. On the numerical solution of the point reactor kinetics equations by generalized Runge-Kutta methods, Nuclear Science and Engineering, 103: 94-99, 1989.

doi: 10.13182/NSE89-A23663

[3] Aboanber AE, Nahla AA. Solution of the point kinetics equations in the presence of Newtonian temperature feedback by Padé approximation via the analytical inversion method, Journal of Physics A: Mathematical and General, 35(45):9609-9627, 2002b.

doi: 10.1088/0305-4470/35/45/309

[4] Aboanber AE, Nahla AA. Generalization of the analytical inverse method for the solution of point kinetics equations, Journal of Physics A: Mathematical and General, 35(14): 3245-3263, $2002 \mathrm{a}$.

doi: 10.1088/0305-4470/35/14/307

[5] Aboanber AE. Analytical solution of the point kinetics equations by exponential mode analysis, Progress in Nuclear Energy, 42(2): 179-197, 2003.

doi: 10.1016/s0140-6701(03)82201-4

[6] Kinard, M.; Allen, E. J.: Efficient numerical solution of the point kinetics equations in nuclear reactor dynamics, Annals of Nuclear Energy, 31(9): 1039-1051, 2004.

doi: 10.1016/j.anucene.2003.12.008

[7] Quintero LB. CORE: a numerical algorithm to solve the point kinetics equations, Annals of Nuclear Energy, 35(11): 2136-2138, 2008.

doi: 10.1016/j.anucene.2008.07.002 
[8] Li H, Chen W, Luo L, Zhu Q. A new integral method for solving the point reactor neutron kinetics equations, Annals of Nuclear Energy, 36(4): 427-432, 2009.

doi: 10.1016/j.anucene.2008.11.033

[9] Nahla, A. A.: Taylor series method for solving the nonlinear point kinetics equations, Nuclear Engineering and Design, 241(5): 1592-1595, 2011.

doi: 10.1016/j.nucengdes.2011.02.016

[10] Hamada, Y. M.: Generalized power series method with step size control for neutron kinetics equations, Nuclear Engineering and Design, 241(8): 3032-3041, 2011.

doi: 10.1016/j.nucengdes.2011.05.006

[11] Hamada YM. Confirmation of accuracy of generalized power series method for the solution of point kinetics equations with feedback, Annals of Nuclear Energy, 55: 184-193, 2013.

doi: 10.1016/j.anucene.2012.12.013

[12] Ganapol BD. A highly accurate algorithm for the solution of the point kinetics equations, Annals of Nuclear Energy, 62: 564$571,2013$.

doi: 10.1016/j.anucene.2012.06.007

[13] Picca P, Furfaro R, Ganapol B. A highly accurate technique for the solution of the non-linear point kinetics equations, Annals of Nuclear Energy, 58: 43-53, 2013.

doi: 10.1016/j.anucene.2013.03.004

[14] Salah A. Hassan SA. Samia.: The Analytical Algorithm for the Differential Transform Method to Solution of the Reactor Pointkinetics Equations, World Applied Sciences Journal, 27(3):367-370, 2013.

doi: 10.5829/idosi.wasj.2013.27.03.1601

[15] Kim HT, Park Y, Kazantzis N, Parlos A, Vista IV F, Chong KT. A numerical solution to the point kinetic equations using Taylor-Lie series combined with a scaling and squaring technique, Nuclear Engineering and Design, 272: 1-10, 2014.

doi: 10.1016/j.nucengdes.2013.12.066 
[16] Patra A, Ray SS. A numerical approach based on Haar wavelet operational method to solve neutron point kinetics equation involving imposed reactivity insertions, Annals of Nuclear Energy, 68: 112-117, 2014.

doi: 10.1016/j.anucene.2014.01.008

[17] Leite QB, Palma AP, Vilhena MT, Bodmann EJ. Analytical representation of the solution of the point reactor kinetics equations with adaptive time step, Progress in Nuclear Energy, 70: 112-118, 2014.

doi: 10.1016/j.pnucene.2013.07.008

[18] Hamada YM. Trigonometric Fourier-series solutions of the point reactor kinetics equations. Nuclear Engineering and Design, 281: 142-153, 2015.

doi: 10.1016/j.nucengdes.2014.11.017

[19] Razak MA, Devan K, Sathiyasheela T. The modified exponential time differencing (ETD) method for solving the reactor point kinetics equations, Annals of Nuclear Energy, 76: 193-199, 2015.

doi: 10.1016/j.anucene.2014.09.020

[20] Nahla AA. Numerical treatment for the point reactor kinetics equations using theta method, eigenvalues and eigenvectors, Progress in Nuclear Energy, 85: 756-763, 2015.

doi: 10.1016/j.pnucene.2015.09.008

[21] Suescún DD, Narváez PM, Lozano PH. Calculation of Nuclear Reactivity Using the Generalised Adams-Bashforth-Moulton Predictor-Corrector Method, Kerntechnik, 81(1): 86-93, 2016.

doi: $10.3139 / 124.110591$

[22] Yun C, Xingjie P, Qing L, Kan W. A numerical solution to the nonlinear point kinetics equations using Magnus expansion, Annals of Nuclear Energy, 89: 84-89, 2016.

doi: 10.1016/j.anucene.2015.11.021

[23] Duderstadt JJ, Hamilton LJ. Nuclear Reactor Analysis, second ed. John Wiley \& Sons Inc., New York, 1976 


\section{Cálculo de densidad de neutrones utilizando el método generalizado de Adams-Bashforth-Moulton}

Resumen: Este artículo presenta una solución numérica a las ecuaciones de cinética puntual para reactores de energía nuclear, un conjunto de siete ecuaciones diferenciales acopladas que describen la variación temporal de la densidad de neutrones y la concentración de precursores de neutrones retardados. Debido a la naturaleza del sistema, proponemos resolver numéricamente las ecuaciones de cinética de puntos mediante la implementación de los métodos de Adams-Bashforth y de AdamsMoulton, que son esquemas predictores-correctores con sus respectivos modificadores para aumentar la precisión. El método propuesto se probó computacionalmente para diferentes formas de reactividad con hasta seis grupos de precursores de neutrones retardados. Este método se utilizó en una publicación reciente para resolver el problema inverso de encontrar la reactividad. Adicionalmente, se muestra que también se puede utilizar para el cálculo de la energía nuclear, que es simple y fácil de implementar, y que produce buenos resultados en comparación con los de la literatura para la densidad de población de neutrones y la concentración de precursores de neutrones retardados.

Palabras clave: densidad nuclear; potencia de reactor nuclear; métodos numéricos; ecuaciones de la cinética puntual. 


\section{Cálculo da densidade de nêutrons usando o método generalizado de Adams-Bashforth-Moulton}

Resumo: Este artigo apresenta uma solução numérica para as equações da cinética pontual para reatores de energia nuclear, um conjunto de sete equações diferenciais acopladas que descrevem a variação temporal da densidade de nêutrons e concentração de precursores de nêutrons atrasados. Devido à natureza do sistema, propomos resolver numericamente as equações da cinética pontual implementando os métodos de Adams-Bashforth e de Adams-Moulton, que são esquemas preditores-corretores com seus respectivos modificadores para aumentar a precisão. O método proposto foi testado computacionalmente para diferentes formas da reatividade com até seis grupos de precursores de nêutrons atrasados. Este método foi usado em uma publicação recente para resolver o problema inverso de encontrar a reatividade. Além disso, mostra-se que também pode ser utilizado para o cálculo da potência nuclear, que é simples e fácil de implementar e que produz bons resultados quando comparado com os da literatura para densidade populacional de nêutrons e concentração de precursores de nêutrons atrasados.

Palavras-chave: densidade nuclear; potência do reator nuclear; métodos numéricos; equações da cinetica pontual. 


\section{Daniel Suescún Díaz}

Is an Assistant Professor of Nuclear Physcis at the Surcolombiana University. He holds two Bachelor degrees, in Mathematics and Physcis from Universidad Industrial de Santander (UIS), Bucaramanga, Colombia. MSc in Physics also from UIS. He received his PhD in Physics of Nuclear Reactors at the Federal University of Rio de Janeiro and a Postdoc from the same university. His main field of research is computational physics applied to nuclear reactors.

ORCID: 0000-0003-2422-0684

\section{Jaime Humberto Lozano Parada}

Lecturer at Universidad Autonoma de Occidente, Colombia. Holds a Bachelor degree in Physics from Universidad Industrial de Santander, Colombia, PhD from Sheffield University, UK, postdoc also from Sheffield. Postdoc from Universidad del Valle, Colombia. Grant holder from: Japanese International Cooperation Agency (JICA), "Es tiempo de Volver" program, and the Newton Fund, Uk. He has writen several papers and patents on plasmas. His main research fields: Plasma Physics and Dynamical Sysytems.

ORCID: 0000-0003-4001-2455

\section{Diego Alejandro Rasero Causil}

Is an Assistant Professor of Solid State Physcis of the at the Surcolombiana University. He holds a graduated degree in Physcis from Universidad de Cordoba, Monteria, Colombia. MSc in Physics also from Universidad de Cordoba, and working toward his $\mathrm{PhD}$ in Physics from Universidad de Sucre. His main research field is computational physics applied to Solid State physcis and Semiconductor Quantum Optics.

ORCID: 0000-0002-6583-0422 